\title{
Cancer risk after medical exposure to radioactive iodine in benign thyroid diseases: a meta-analysis
}

\author{
Trinh Trung Hieu ${ }^{1,2}$, Anthony W Russel ${ }^{3,4}$, Ross Cuneo ${ }^{3}$, Justin Clark ${ }^{5}$, \\ Tomas Kron ${ }^{6}$, Per Hall ${ }^{7}$ and Suhail A R Doi ${ }^{1,3}$
}

\author{
${ }^{1}$ School of Population Health, University of Queensland, Brisbane, Queensland, Australia \\ ${ }^{2}$ Department of Clinical Pharmacy, Hanoi University of Pharmacy, Hanoi, Vietnam \\ ${ }^{3}$ Department of Endocrinology, Princess Alexandra Hospital, Brisbane, Queensland, Australia \\ ${ }^{4}$ School of Medicine and ${ }^{5}$ Herston Health Sciences Library, University of Queensland, Brisbane, Queensland, Australia \\ ${ }^{6}$ Physical Sciences Department, Peter MacCallum Cancer Centre, Melbourne, Victoria, Australia \\ ${ }^{7}$ Department of Medical Epidemiology and Biostatistics, Karolinska Institute, Stockholm, Sweden \\ (Correspondence should be addressed to S A R Doi at School of Population Health, University of Queensland; \\ Email: sardoi@gmx.net)
}

\begin{abstract}
Radioiodine-131 $\left({ }^{131} \mathrm{I}\right)$ is widely used for diagnosis and treatment of benign thyroid diseases. Observational studies have not been conclusive about the carcinogenic potential of ${ }^{131}$ I and we therefore conducted a meta-analysis. We performed a literature search till September 2011 which included ${ }^{131} \mathrm{I}$ as a diagnostic or treatment modality $\left({ }^{131} \mathrm{I}\right.$ for treatment of thyroid cancer was excluded). Data on 64 different organ or organ group subsets comprising 22029 exposed subjects in the therapeutic cohorts and 24799 in the diagnostic cohorts in seven studies were included. Outcome was pooled as the relative risk (RR) using both standard and bias adjusted methods. Quality assessment was performed using a study-specific instrument. No increase in overall (RR 1.06, 95\% Cl: 0.94-1.19), main organ group or combined organ group (four groups known to concentrate ${ }^{131} \mathrm{I}$; RR $1.11,95 \% \mathrm{Cl}$ : 0.94-1.31) risks was demonstrable. Individual organs demonstrated a higher risk for kidney (RR 1.70, 95\% Cl: 1.15-2.51) and thyroid (RR 1.99, 95\% Cl: 1.22-3.26) cancers with a strong trend for stomach cancer (RR 1.11, 95\% Cl: 0.92-1.33). A thyroid dose effect was seen for diagnostic doses. While there is no increase in the overall burden of cancer, an increase in risk to a few organs is seen which requires substantiation. The possible increase in thyroid cancer risk following diagnostic ${ }^{131}$ I use should no longer be of concern given that it has effectively been replaced by the use of $99 \mathrm{mTc}$-pertechnetate.
\end{abstract}

Endocrine-Related Cancer (2012) 19 645-655

\section{Introduction}

Among many radionuclides used in nuclear medicine, radioiodine-131 $\left({ }^{131} \mathrm{I}\right)$ (physical half-life $\sim 8$ days) plays an important role and has been used successfully for seven decades. Since its introduction in 1941 (Chapman \& Evans 1946, Hertz \& Roberts 1946), it is likely that millions of patients with benign thyroid disease have been administered therapeutic or diagnostic activities of ${ }^{131} \mathrm{I}$. The ease of its administration (Ross 2011), lack of significant adverse effects (Read et al. 2004) and low cost (Ross 2011) have prompted such widespread use even though there still remains some uncertainty in terms of its carcinogenic potential
(Glinoer et al. 1987, Solomon et al. 1990, Tominaga et al. 1997, Walsh 2000, Lucignani 2007). In favour of ${ }^{131}$ I therapy, however, is the fact that the radiation dose to the thyroid is so high that in most cases a large mass of the thyroid gland is ablated and absorbed dosages to other organs are very low (ICRP 1987). It is, however, only in Graves' disease that ${ }^{131} \mathrm{I}$ treatment achieves such high tissue doses that the thyroid epithelial cells are destroyed. With toxic nodules or toxic goitre, the attempt is to achieve lethal tissue doses in the hyperactive tissue while trying to avoid lethal doses in the 'healthy' tissue. So there is a possibility that we do induce carcinogenesis in the remaining gland. 
This is in contrast to external radiotherapy where doses are in the intermediate range to surrounding organs, resulting in sub-lethal cellular damage. Although the carcinogenic effects of moderate doses of therapeutic $\mathrm{X}$-radiation and gamma radiation are fairly well described (Ron 2003), it is likely that risks after exposure to ${ }^{131} \mathrm{I}$ are much less given that the thyroid concentrates most of the radioiodine, and doses to most organs are very small $(0.04-0.14 \mathrm{mGy} / \mathrm{MBq}$; Zanzonico 2000) and delivered over several days.

Several long-term cohort studies from groups in Sweden (Holm et al. 1991), England (Franklyn et al. 1999), Finland (Metso et al. 2007) and the US (Hoffman et al. 1982, Goldman et al. 1988) that have investigated the relationship between cancer risk following therapeutic use of ${ }^{131} \mathrm{I}$ in benign thyroid disease provide conflicting results. For example, studies report an increase (Holm et al. 1991, Metso et al. 2007), a decrease (Franklyn et al. 1999) or no change (Hoffman et al. 1982) in overall cancer risk. Also, reports on increased breast (Metso et al. 2007), kidney (Holm et al. 1991) and thyroid (Hoffman et al. 1982, Franklyn et al. 1999) cancer risks are contradicted by other reports on breast (Hoffman et al. 1982, Goldman et al. 1988, Holm et al. 1991, Franklyn et al. 1999), kidney (Hoffman et al. 1982, Metso et al. 2007) or thyroid cancers (Holm et al. 1991, Metso et al. 2007). A recent overview of this topic by Verburg et al. (2011) suggests that the evidence is not conclusive in favour of increased risk. However, as individual studies on their own are unlikely to answer this important question, we decided to embark on a metaanalysis of the evidence available. Also, cancer is a rare outcome, so in order to estimate the incidence of cancers after exposure to ${ }^{131} \mathrm{I}$, long periods of followup and a large population is required which could be addressed by meta-analysis.

\section{Materials and methods}

\section{Data sources and eligibility criteria}

The medical literature, till September 2011, was searched for articles reporting on the diagnostic or therapeutic use of ${ }^{131} \mathrm{I}$ in benign thyroid diseases and the development of cancer. The references of selected articles were cross-checked for further studies and other language publications were translated where deemed necessary. Details of the search strategy and databases searched are in Supplementary Materials and methods 1 , see section on supplementary data given at the end of this article. Inclusion was limited to human studies with exclusions made for ${ }^{131}$ I exposure in thyroid cancer (therapeutic or diagnostic), in nuclear accidents and reports of a non-analytic observational design.

\section{Data abstraction and quality assessment}

A data extraction table was completed for each study (see Results). A methodological quality checklist was developed based on a modification of the general checklist created by Doi \& Thalib (2008) (see Supplementary Materials and methods 2, see section on supplementary data given at the end of this article). The maximum score was ten points and quality was assessed by two independent reviewers. Any discrepancies were addressed by consensus.

\section{Statistical analysis}

The primary outcome was the relative risk (RR) or the standardised incidence ratio (SIR) for those exposed to radioiodine compared with those not exposed or a standardised population respectively. The SIR was defined as the number of cases observed in the study population divided by the number of cases that would be expected in a standardised population. The RR was defined as the risk of developing a cancer within the follow-up time compared with a control group. SIR and RR were stratified by cancer site. The SIR was used as an estimate of the RR and we report the pooled RR in this meta-analysis. The latter was justified because both the prevalence of cancer and the RR for cancer is expected to be low (Chaturvedi et al. 2008). Heterogeneity was determined to be present when the calculated value of $\tau^{2}$ was greater than zero and/or the Q-statistic was significant at $P<0.1$ (Takkouche et al. 1999). Studies were pooled using the quality-effects (QE) model (Doi \& Thalib 2008, Doi et al. 2011) to take advantage of both bias adjustment (Doi et al. 2011) and additional weighting by the incidence of cancers (AIHW 1998) in the population at large because incidence differs widely by cancer type, and failure to consider this would not reflect the overall burden of risk. This sort of weighting has been applied by us previously (Jamal et al. 2012) and though the latter is not possible with routine models of meta-analysis, we also report a sensitivity analysis using the conventional fixed effects model for homogenous studies and random effects model for heterogeneous studies.

Finally, a subgroup analysis was conducted by computing the ratios of SIRs (Morris \& Gardner 1988; RSIR and 95\% CI) in subgroups (defined by duration of follow-up, dose/activity of ${ }^{131}$ I and age at the time of exposure; see Supplementary Materials and methods 3 , see section on supplementary data given at 
the end of this article). To check for publication bias, funnel plot asymmetry could not be used as we had few studies in each group. However, an exclusion sensitivity analysis was performed to check the impact of individual studies by excluding each study and calculating the overall effects again. All analyses were done using MetaXL version 1.2 (http://www.epigear.com).

\section{Results}

2929 unique abstracts were reviewed and the full texts of 24 studies were retrieved (Fig. 1). Seventeen of these were then excluded because they were not found to address ${ }^{131}$ I use $(n=3$; Berlin \& Wasserman 1976, Hoffman et al. 1984, Mellemgaard et al. 1998), did not report effect sizes (RR or SIR; Munoz et al. 1978), were descriptive studies $(n=7$; Pochin 1960, Dobyns et al. 1974, Freitas et al. 1979, Spencer et al. 1983, Ozaki et al. 1994, Angusti et al. 2000, Listewnik et al. 2010) or had overlapping datasets ( $n=6$; Saenger et al. 1968, Holm et al. 1980, 1988, Hall \& Holm 1995a,b, Hall et al. 1996). Seven studies were finally selected for this meta-analysis (Hoffman et al. 1982, Goldman et al. 1988, Holm et al. 1991, Franklyn et al. 1999, Hahn et al. 2001, Dickman et al. 2003, Metso et al. 2007).

\section{Characteristics of the included studies}

We included 64 different organ or organ group subsets in five therapeutic (Hoffman et al. 1982,
Goldman et al. 1988, Holm et al. 1991, Franklyn et al. 1999, Metso et al. 2007) and two diagnostic studies (Hahn et al. 2001, Dickman et al. 2003). There were 22029 exposed subjects in the therapeutic cohorts and 24799 in the diagnostic cohorts (see Table 1). Although the data source in the study by Dickman et al. (2003) overlapped with the study by Holm et al. (1991), the focus was diagnostic in the former study; and patients with therapeutic use of ${ }^{131}$ I were excluded. The population considered in these studies originated from the US, Sweden, Finland, UK and Germany. The mean follow-up time varied from 9.8 to 27 years. RRs were estimated in three studies (Hoffman et al. 1982, Hahn et al. 2001, Metso et al. 2007), while the other four studies reported SIRs (Goldman et al. 1988, Holm et al. 1991, Franklyn et al. 1999, Dickman et al. 2003). The quality scores of studies ranged from five to eight out of ten. All of seven studies were retrospective (see Supplementary Table 1, see section on supplementary data given at the end of this article for further details regarding each study). The diagnostic studies reported only on thyroid cancer risk.

\section{Ascertainment of cancer diagnosis}

In all seven studies, cancer was the main endpoint retrospectively ascertained. Three studies (Hoffman et al. 1982, Goldman et al. 1988, Hahn et al. 2001) used either questionnaires, telephone interview, autopsy reports (if available) or medical records

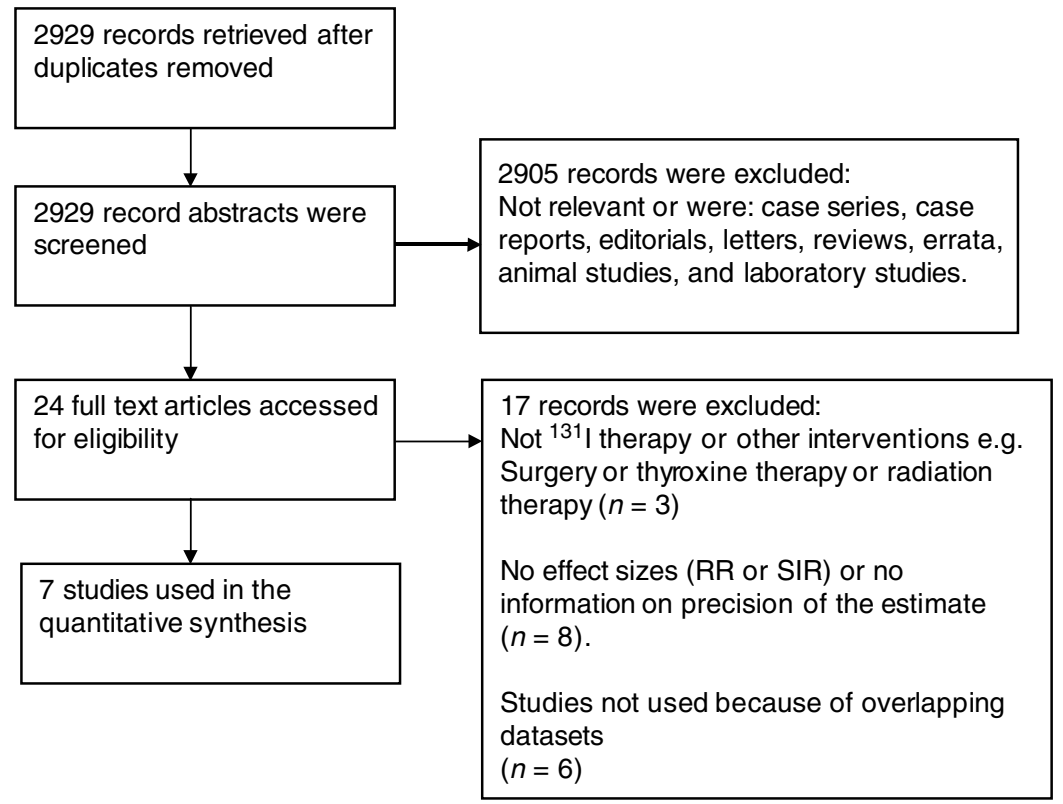

Figure 1 Flow diagram of the literature search for the meta-analysis. 
Table 1 Characteristics of the included studies

\begin{tabular}{|c|c|c|c|c|c|}
\hline Study & $\begin{array}{l}\text { Reason } \\
\text { for exposed } \\
\text { to }{ }^{131} \text { I }\end{array}$ & $\begin{array}{l}\text { Number of } \\
\text { exposed } \\
\text { subjects in } \\
\text { final cohort }\end{array}$ & Exposed group & Comparison group & $\begin{array}{l}\text { Activities of } \\
{ }^{131} \text { I used (mean) }\end{array}$ \\
\hline $\begin{array}{l}\text { Hoffman et al. } \\
\text { (1982) }\end{array}$ & Therapeutic & 1005 & $\begin{array}{l}\text { Hyperthyroid women } \\
\text { treated with }{ }^{131} \text { I at } \\
\text { Mayo clinic from } \\
01 / 01 / 1946 \text { to } \\
31 / 12 / 1964\end{array}$ & $\begin{array}{l}\text { Hyperthyroid women } \\
\text { assigned to surgical } \\
\text { treatment in Mayo clinic } \\
\text { from } 01 / 01 / 1946 \text { to } \\
31 / 12 / 1964\end{array}$ & $\begin{array}{l}\text { 392.2 MBq (equivalent to } \\
10.6 \mathrm{mCi} \text { ) }\end{array}$ \\
\hline $\begin{array}{l}\text { Goldman et al. } \\
\text { (1988) }\end{array}$ & Therapeutic & $607^{\mathrm{a}}$ & $\begin{array}{l}\text { Hyperthyroid women } \\
\text { treated with }{ }^{131} I \text { at } \\
\text { Massachusetts } \\
\text { General Hospital } \\
\text { Thyroid Unit from } \\
\text { 01/01/1946 to } \\
31 / 12 / 1964\end{array}$ & $\begin{array}{l}\text { Cause- age- calendar } \\
\text { year- time- } \\
\text { sex-matched cancer } \\
\text { incidence data in } \\
\text { Connecticut from } \\
01 / 01 / 1946 \text { to } \\
31 / 12 / 1964\end{array}$ & $\begin{array}{l}\text { NA (approximately equal } \\
\text { numbers of women } \\
\text { were administered } \\
<240,240-369 \text { and } \\
\geq 370 \mathrm{MBq} \text { ) }\end{array}$ \\
\hline $\begin{array}{l}\text { Holm et al. } \\
\quad(1991)\end{array}$ & Therapeutic & 10207 & $\begin{array}{l}\text { Hyperthyroid patients } \\
\text { treated with }{ }^{131} \text { I in } \\
\text { seven Swedish } \\
\text { hospitals from } 1950 \\
\text { to } 1975\end{array}$ & $\begin{array}{l}\text { Age- sex- region of } \\
\text { residence- calendar } \\
\text { year-matched cancer } \\
\text { incidence data in } \\
\text { Sweden from } 1958 \\
\text { to } 1985\end{array}$ & $506 \mathrm{MBq}$ \\
\hline $\begin{array}{l}\text { Franklyn et al. } \\
\text { (1999) }\end{array}$ & Therapeutic & 7417 & $\begin{array}{l}\text { Hyperthyroid patients } \\
\text { treated with }{ }^{131} \text { I in the } \\
\text { West Midlands region } \\
\text { of the UK from } 1950 \text { to } \\
1991\end{array}$ & $\begin{array}{l}\text { Age- sex- calendar } \\
\text { year-matched cancer } \\
\text { incidence data in } \\
\text { England and Wales } \\
\text { from } 1950 \text { to } 1991\end{array}$ & $308 \mathrm{MBq}(\mathrm{s} . \mathrm{D} .=232 \mathrm{MBq})$ \\
\hline $\begin{array}{l}\text { Hahn et al. } \\
\qquad(2001)\end{array}$ & Diagnostic & 789 & $\begin{array}{l}\text { Children examined for } \\
\text { suspected thyroid } \\
\text { disease with }{ }^{131} \mathrm{I} \text { in } \\
10 \text { German hospitals } \\
\text { from } 1989 \text { to } 1997\end{array}$ & $\begin{array}{l}\text { Children examined for } \\
\text { suspected thyroid } \\
\text { disease with other } \\
\text { methods than using }{ }^{131} \text { I } \\
\text { in ten German hospitals } \\
\text { from } 1989 \text { to } 1997\end{array}$ & $\begin{array}{l}0.9 \mathrm{MBq}^{\mathrm{b}} \text { (interquartile } \\
\text { range } 0.4-1.5 \text {; median } \\
\text { thyroid-absorbed dose } \\
1 \mathrm{~Gy} \text { ) }\end{array}$ \\
\hline $\begin{array}{l}\text { Dickman et al. } \\
\text { (2003) }\end{array}$ & Diagnostic & $24010^{c}$ & $\begin{array}{l}\text { Patients examined with } \\
{ }^{131} \text { I in seven Swedish } \\
\text { hospitals from } 1952 \text { to } \\
1969\end{array}$ & $\begin{array}{l}\text { Age- sex- region of } \\
\text { residence- calendar } \\
\text { year-matched cancer } \\
\text { incidence data in } \\
\text { Sweden from } 1958 \\
\text { to } 1969\end{array}$ & $\begin{array}{l}1.6 \mathrm{MBq}^{\mathrm{d}} \text { (mean } \\
\text { thyroid-absorbed dose } \\
0.94 \mathrm{~Gy} \text { ) }\end{array}$ \\
\hline $\begin{array}{l}\text { Metso et al. } \\
\quad(2007)\end{array}$ & Therapeutic & 2793 & $\begin{array}{l}\text { Hyperthyroid patients } \\
\text { treated with }{ }^{131} \mathrm{I} \text { in } \\
\text { Tampere University } \\
\text { Hospital, Finland from } \\
01 / 1965 \text { to } 06 / 2002\end{array}$ & $\begin{array}{l}\text { Age- and sex-matched } \\
\text { group from the } \\
\text { Population Register } \\
\text { Centre of Finland }\end{array}$ & $305 \mathrm{MBq}$ \\
\hline
\end{tabular}

${ }^{\mathrm{a}}$ Number of patients who were exposed to ${ }^{131}$ I only.

${ }^{\mathrm{b}}$ The median ${ }^{131} \mathrm{I}$ activity administered.

${ }^{\mathrm{C}}$ Number of ${ }^{131} \mathrm{I}$-exposed patients who did not report previous radiotherapy to the neck and were not referred for suspicion of a thyroid tumour.

${ }^{\mathrm{d}}$ Mean activity administered to patients who did not report previous radiotherapy to the neck region and were not referred for suspicion of a thyroid tumour.

from the Cooperative Thyrotoxicosis Therapy Follow-up Study.

Four studies (Holm et al. 1991, Franklyn et al. 1999, Dickman et al. 2003, Metso et al. 2007) used more robust methods as data were retrieved from national cancer registries to identify cancer types from Sweden (Holm et al. 1991, Dickman et al. 2003), Finland (Metso et al. 2007) and the UK (Franklyn et al. 1999).

\section{Quantitative synthesis of data (therapeutic use only)}

\section{Overall cancer risk}

Seven main organ groups from five studies (Hoffman et al. 1982, Goldman et al. 1988, Holm et al. 1991, Franklyn et al. 1999, Metso et al. 2007; Fig. 2) suggest that there was no overall increase in cancer risk 
(a)

Including Franklyn, 1999 (Franklyn et al., 1999)

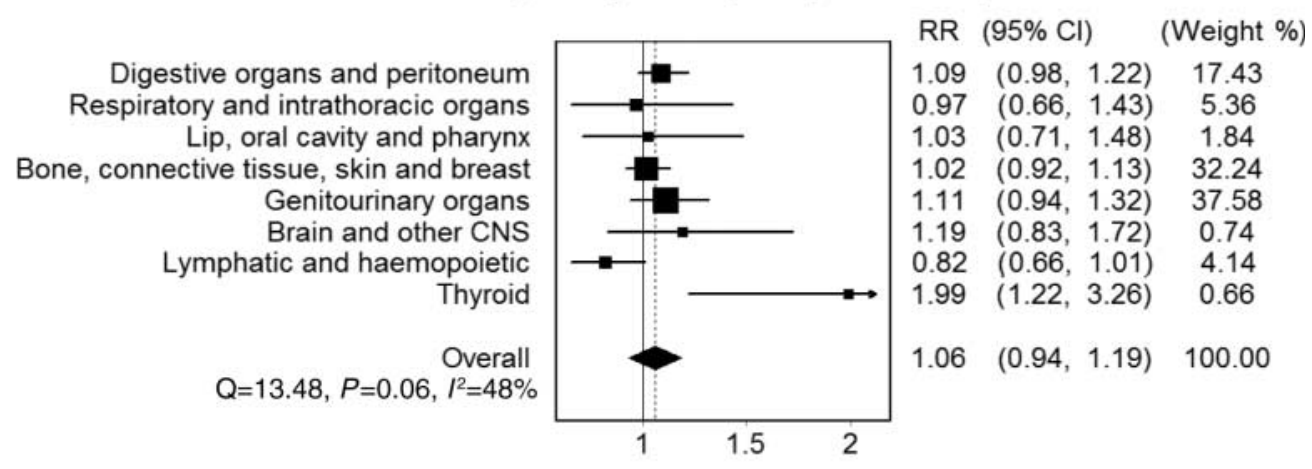

(b)

Excluding Franklyn, 1999 (Franklyn et al., 1999)

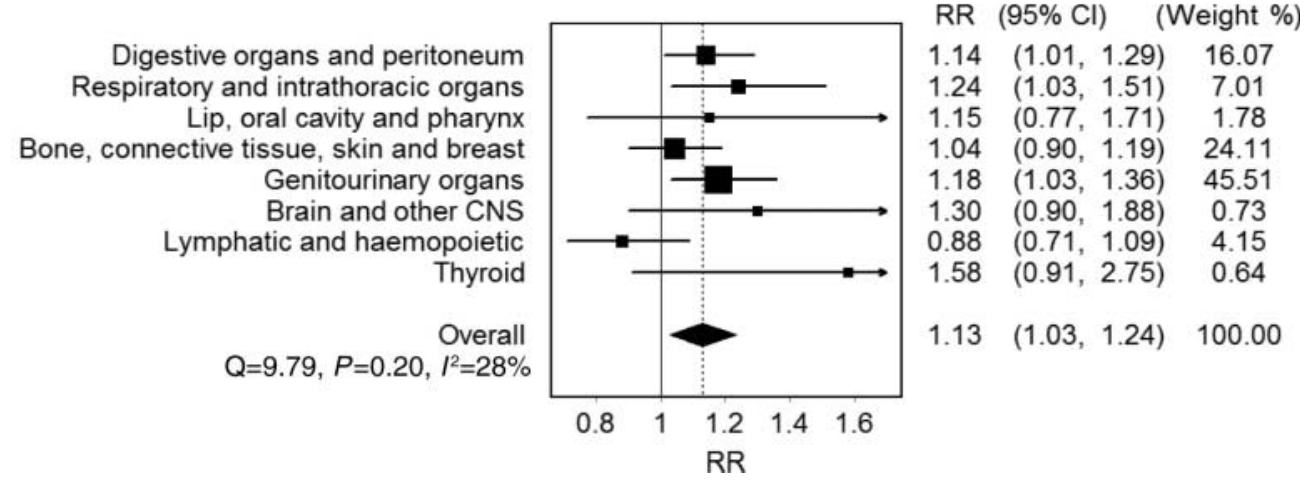

Figure 2 The meta-analysis forest plot depicting the overall burden of cancer risk from ${ }^{131} \mathrm{I}$ on eight major groups of organs (QE model; a) including Franklyn et al. (1999) and (b) excluding Franklyn et al. (1999).

(RR 1.06, 95\% CI: 0.94-1.19; Fig. 2a). Results were sensitive to exclusion of the study by Franklyn et al. (1999), exclusion of which increased the pooled risk of cancer (RR 1.13, 95\% CI: 1.03-1.24; Fig. 2b). Conventional weighting methods (no population or bias weights) concurred with a RR of 1.03 (95\% CI: 0.94-1.13) compared with a RR of $1.12(95 \%$ CI: 1.04-1.20) when the study by Franklyn et al. (1999) was excluded.

\section{Organ groups that concentrate ${ }^{131}$ I}

Four organ groups known to concentrate radioiodine (digestive organs and peritoneum; lip, oral cavity and pharynx; genitourinary organs and thyroid) revealed no increase in risk (RR 1.11, 95\% CI: 0.94-1.31). Results were sensitive to exclusion of the study by Franklyn et al. (1999) after which risk increased (RR 1.17, 95\% CI: 1.06-1.30). The latter was mainly because the study by Franklyn et al. (1999) had protective estimates for digestive and genitourinary organs. Similar results were obtained with conventional weighting (RR 1.06, 95\% CI: 0.98-1.13) compared with RR 1.12 (95\% CI: 1.04-1.21) after removal of the study by Franklyn et al. (1999)).

\section{Individual organ groups}

Seven organ groups (Fig. 2) from five papers did not demonstrate an increase in cancer risk (Supplementary Figure 1, see section on supplementary data given at the end of this article). Digestive and respiratory organs groups were, however, sensitive to exclusion of the study by Franklyn et al. (1999), resulting in borderline significance in favour of increased risk (lower confidence limit of 1.01-1.03, Fig. 2b). Conventional weighting methods suggest a slight difference in direction of the pooled estimate for digestive organs and peritoneum; lip, oral cavity and pharynx; and bone, connective tissues, skin and breast, although none were significant and were most likely random changes (see Supplementary Figure 2, see section on supplementary data given at the end of this article).

\section{Individual organs}

Nine individual organs (salivary glands, breast, kidney, bladder, lymphoma, leukaemia, pancreas, stomach and thyroid) reported by five studies reveal a higher risk of only kidney and thyroid cancers, while stomach cancer demonstrated a non-significant trend (Supplementary 
Figure 1, see section on supplementary data given at the end of this article).

The kidney cancer RR was 1.70 (95\% CI: 1.15-2.51) from data in three studies. Exclusion of the study by Metso et al. (2007) decreases the significance of the kidney cancer result and puts most of the weight on the study by Holm et al. (1991).

The thyroid cancer risk (RR: 1.99, 95\% CI: 1.22-3.26) was mitigated by excluding the study by Franklyn et al. (1999), resulting in an RR of 1.58 (95\% CI: 0.91-2.75). These studies had less than ten observed cases of thyroid cancer (Hoffman et al. 1982, Franklyn et al. 1999, Metso et al. 2007) and the study by Holm et al. (1991) with 18 observed cases did not demonstrate increased risk. Conventional weighting methods concurred with these results (see Supplementary Figure 2, see section on supplementary data given at the end of this article).

Finally, the only two studies, Hahn et al. (2001) and Dickman et al. (2003), on diagnostic ${ }^{131}$ I use (pooled separately) did not demonstrate an increase in thyroid cancer risk $(\mathrm{RR}=1.06,95 \% \mathrm{CI}: 0.62,1.82)$. However, one of these studies was on children only (Hahn et al. 2001) while the other (Dickman et al. 2003) was predominantly undertaken on adults (only $7 \%$ were below the age of 20 years). The RR (or SIR) for thyroid cancer was 0.9 (95\% CI: 0.1-5.1) in childhood exposure vs 0.91 (95\% CI: $0.64-1.26$ ) in adult exposure (excluding subjects with prior radiation therapy or referred for suspicion of a tumour). The risks in the adult study (Dickman et al. 2003) were significantly higher with prior radiation with (SIR 13.66; 95\% CI: 7.06-23.87) or without (SIR 7.67; 95\% CI: 3.96-13.40) referral for a thyroid tumour.

\section{Stratification by time since exposure, age at exposure, absorbed dose and administered activity of ${ }^{131}$ I}

To examine the effect of time since exposure, age at exposure and dose of ${ }^{131} \mathrm{I}$ on cancer risk, we calculated the ratio of the SIRs (RSIR) using data from three studies that used this effect size and reported subgroups (Goldman et al. 1988, Hall et al. 1992, Dickman et al. 2003; Table 2). This was done in lieu of a subgroup meta-analysis because there was not enough data to perform a stratified analysis.

Time since exposure to ${ }^{131} \mathrm{I}$ had a significant effect only on stomach cancer with the ratio of SIRs of 1.77 (95\% CI: $1.03-3.53$ ) and the $>15$ year SIR showing a statistically significant increase.

Thyroid dose after diagnostic and therapeutic activity administration was compared in two studies (Hahn et al. 2001, Dickman et al. 2003). The diagnostic study (Dickman et al. 2003) demonstrated that the patients with an absorbed dose $>1$ Gy had 2.82 times the SIR compared with patients with an absorbed dose of $<0.25$ Gy (ratio of SIRs $2.82,95 \%$ CI: 1.22-14.89), although neither of the stratumspecific SIRs were significant. The therapeutic study (Goldman et al. 1988) reported that $>10 \mathrm{mCi}$ compared with no administration of ${ }^{131} \mathrm{I}$ did not significantly alter SIR estimates.

Finally, there was no trend of increasing SIR of thyroid cancer as age at exposure to ${ }^{131} \mathrm{I}$ for diagnostic use decreased (Dickman et al. 2003; RSIR $=1.06$; 95\% CI: 0.44-2.40) when those 20-50 years old were compared with those $>50$ years old.

\section{Discussion}

\section{Overall burden of cancer risk}

Although case reports of several cancers (Kennedy \& Fish 1959, McCormack \& Sheline 1963, Bundi et al. 1977, Munoz et al. 1978, Spencer et al. 1983) after radioactive iodine treatment have raised question about the carcinogenesis of ${ }^{131} \mathrm{I}$, the evidence from this metaanalysis is lacking. In exposed patients, there was no increase in cancer risk overall. Individual organ groups as well as a combination of organ groups (CG) known to concentrate radioiodine (salivary glands, digestive tract and urinary tract) did not demonstrate an increased risk of cancer. Individual studies on overall (Holm et al. 1991, Metso et al. 2007) or CG (Hoffman et al. 1982) risks report a slight increase in cancer but the overall burden of risk by our population-weighted estimate as well as conventional models concurred suggesting that overall burden of risk was null.

\section{Thyroid}

Lack of an overall increase in burden of cancer risk is consistent with the low levels of organ doses expected from ${ }^{131} \mathrm{I}$ exposure that remain far from the reported dangerous threshold of between 100 and $1000 \mathrm{mGy}$ (Kloos 2011). This level of exposure is reached, after ${ }^{131}$ I administration, within the thyroid, but is thought to be less important because the thyroid is ablated and tissue does not remain for carcinogenesis to ensue. Also, while a significant risk of thyroid cancer has been observed after administration of therapeutic $\mathrm{X}$-irradiation with doses as high as $60 \mathrm{~Gy}$ in childhood (de Vathaire et al. 1988, Tucker et al. 1991), this has not been observed in several large cohort studies after use of a similar radiation-absorbed dose of ${ }^{131} \mathrm{I}$ for treatment of hyperthyroidism (Dobyns et al. 1974, 
Table 2 Subgroup analysis by duration of follow-up, administered ${ }^{131} \mathrm{I}$ activity, absorbed dose or age at exposure

\begin{tabular}{|c|c|c|c|c|c|}
\hline Study & $\begin{array}{l}\text { Types of cancer (observed cases in } \\
\text { group } 1 \text { vs group 2) }\end{array}$ & SIR1 & SIR2 & $\begin{array}{l}\text { Ratio of } \\
\text { SIR's }\end{array}$ & $95 \% \mathrm{Cl}$ \\
\hline \multicolumn{6}{|l|}{ Duration of follow-up } \\
\hline \multirow[t]{3}{*}{ Goldman et al. (1988) } & All cancer (16 vs 47$)$ & $\geq 30$ years & $<10$ years & 1.33 & $0.67-2.22$ \\
\hline & Breast (5 vs 14 ) & & & 1.50 & $0.29-3.59$ \\
\hline & Pancreas (6 vs 3 ) & 20-29 years & & 1.88 & $0.53-36.14$ \\
\hline \multirow[t]{12}{*}{ Holm et al. (1991) } & All cancer & $\geq 15$ years & $1-4$ years & 0.98 & $0.85-1.14$ \\
\hline & Breast & & & 0.88 & $0.63-1.24$ \\
\hline & Pancreas (16 vs 6 ) & & & 1.59 & $0.70-6.29$ \\
\hline & Leukaemia (12 vs 8 ) & & & 1.04 & $0.44-3.06$ \\
\hline & Thyroid (4 vs 4) & & & 0.86 & $0.16-4.77$ \\
\hline & Parathyroid (11 vs 8 ) & & & 0.64 & $0.26-1.86$ \\
\hline & Stomach (35 vs 16) & & & 1.77 & $1.03-3.53$ \\
\hline & $\begin{array}{l}\text { Liver, gallbladder and bile ducts } \\
\quad(9 \text { vs } 17)\end{array}$ & & & 0.96 & $0.45-2.60$ \\
\hline & Lung (30 vs 25) & & & 0.77 & $0.45-1.34$ \\
\hline & Kidney (14 vs 14) & & & 0.73 & $0.34-1.60$ \\
\hline & Bladder (14 vs 7 ) & & & 1.21 & $0.52-3.98$ \\
\hline & Brain (13 vs 8 ) & & & 1.40 & $0.60-4.10$ \\
\hline Dickman et al. (2003) ${ }^{a}$ & Thyroid (15 vs 4 ) & $\geq 20$ years & $2-5$ years & 0.69 & $0.28-6.61$ \\
\hline \multicolumn{6}{|l|}{ Therapeutic activity } \\
\hline \multirow[t]{6}{*}{ Goldman et al. (1988) } & All malignant neoplasms (48 vs 41 ) & $\begin{array}{r}\geq 370 \mathrm{MBq} \\
(10 \mathrm{mCi})\end{array}$ & No ${ }^{131}$ I & 1.00 & $0.65-1.61$ \\
\hline & All digestive organs (13 vs 13 ) & & & 0.82 & $0.35-2.40$ \\
\hline & Pancreas (3 vs 2) & & & 0.76 & $0.10-50.07$ \\
\hline & Breast (18 vs 18) & & & 1.50 & $0.73-3.81$ \\
\hline & Brain (3 vs 1) & & & 2.50 & $0.40-82.50$ \\
\hline & All other sites (14 vs 9 ) & & & 0.78 & $0.36-1.74$ \\
\hline \multicolumn{6}{|l|}{ Diagnostic-absorbed dose ${ }^{b}$} \\
\hline Dickman et al. (2003) ${ }^{a}$ & Thyroid (16 vs 5) & $>1.00 \mathrm{~Gy}$ & $\leq 0.25 \mathrm{~Gy}$ & 2.82 & $1.22-14.89$ \\
\hline \multicolumn{6}{|l|}{ Age at exposure } \\
\hline Dickman et al. $(2003)^{a}$ & Thyroid (2 vs 11) & $\leq 20$ years & $>50$ years & 1.02 & $0.00-3.02$ \\
\hline Dickman et al. (2003) ${ }^{a}$ & Thyroid (23 vs 11 ) & $20-50$ years & & 1.06 & $0.44-2.40$ \\
\hline
\end{tabular}

${ }^{a}$ Calculated from patients who did not report previous XRT to the neck region and were not referred for suspicion of a thyroid tumour. ${ }^{\mathrm{b}}$ The quality factor for all radiations emitted by ${ }^{131} \mathrm{I}$ is assumed to be unity and thus doses in Gray are equivalent to doses in Sievert.

Holm et al. 1980, 1991, Goldman et al. 1988, Angusti et al. 2000, Metso et al. 2007).

The two studies that demonstrate an increase in the risk of thyroid cancer (Hoffman et al. 1982, Franklyn et al. 1999) differ from the other studies. The study by Hoffman et al. (1982) reports an RR 9.1 but this result was based on three cases in the ${ }^{131}$ I group and one case in the control (surgical) group (Hoffman et al. 1982). There was a tendency toward increased risk for women $<40$ years old and decreased risk with increasing age at exposure (Hoffman et al. 1982). This result could have been biased by medical screening following treatment of hyperthyroidism, patient selection bias, choice of surgically treated patients as control groups and limited observation time. In the case of the study by Franklyn et al. (1999) data on cancer incidence (for patients and controls) were drawn from different sources, so bias was likely. Franklyn et al. (1999) compared site-specific data on cancer incidence from follow-up with data from England and Wales in preference to comparison with incidence from the study region because regional control data were incomplete and about $20 \%$ of patients had moved from the region before study completion. Indeed, after exclusion of the study by Franklyn et al. (1999) our pooled estimate for thyroid cancer (RR 1.99; 95\% CI: 1.22-3.26) declines to non-significance (RR 1.58; 95\% CI: $0.91-2.75)$ and this is contrary to the protective trend seen for other cancers.

Overall, there is the problem of confounding by indication in studies that report increased risk as thyroid cancer is far more common in those with nodular thyroid disease (as compared with Graves'; Angusti et al. 2000). Also thyroid cancer, if associated with Graves' disease, is found more commonly in surgically treated patients than in patients after ${ }^{131} \mathrm{I}$ therapy (Behar et al. 1986). Indeed, under 20-year-old individuals who did not presumably have nodular 
disease and who received ${ }^{131} \mathrm{I}$ for Graves' disease, followed-up for 36 years, revealed no cases of thyroid cancer (Read et al. 2004). Also, stratification by duration of follow-up (Holm et al. 1991) did not result in a significant increase in the SIR for thyroid cancer.

Diagnostic ${ }^{131}$ I use had no increase in risk demonstrable, and this concurs with several studies of diagnostic ${ }^{131}$ I use in children or adolescents (Holm et al. 1988, Hall et al. 1996, Hahn et al. 2001, Dickman et al. 2003). There was also no increase in SIR when stratification by duration of follow-up or age at exposure was done (Dickman et al. 2003). It has been estimated that for an adult, assuming a $15 \%$ uptake, a thyroid scan with $1.85-7.4 \mathrm{MBq}{ }^{131} \mathrm{I}$ orally exposes the thyroid to 388-1554 mGy (SNM 1999) and the study by Dickman et al. (2003) demonstrated an increased SIR when the dose was $>1000 \mathrm{mGy}$ as compared with $<250 \mathrm{mGy}$. This might be of concern given that this was an absorbed dose to a non-ablated thyroid gland. Nowadays, however, it is much more common to use $75-370 \mathrm{MBq} 99 \mathrm{mTc}-$ pertechnetate i.v., which results in a much lower thyroid exposure, with the highest exposure being to the upper large intestine to the order of 5-23 mGy.(SNM 1999). While there is little evidence to suggest that the use of diagnostic ${ }^{131} \mathrm{I}$ in adults is carcinogenic, additional data are needed to clarify the risks associated with childhood medical exposure (Ron 2003).

\section{Other organs}

Doses to other organs are quite low and an excess of cancers has never been detected for doses below $100 \mathrm{mGy}$ (Kloos 2011), and after repeated X-ray examinations, an excess of cancer is reported only for cumulative doses $>500 \mathrm{mGy}$ (Vaiserman 2010). Suit et al. have reviewed secondary carcinogenesis after radiation exposure and conclude that the factorial decrease in risk of radiation-induced secondary cancer would be greatest for reduction in dose levels below 2 Gy. This dose is not reached in any organ (other than the thyroid) after ${ }^{131}$ I therapy (Suit et al. 2007) and doses to other organs (apart from the stomach) parallel doses received from common medical imaging procedures, ranging up to $20 \mathrm{mGy}$ (highest for chest/ abdominal CT and coronary angiography).

The highest non-thyroidal exposure is reported to be the stomach at about $0.41 \mathrm{mGy} / \mathrm{MBq}$ (Zanzonico 2000), the total dose averaging $250 \mathrm{mGy}$ (Edmonds \& Smith 1986, Huysmans et al. 1996). Within the gastrointestinal system, the stomach is most exposed, since ingested ${ }^{131} \mathrm{I}$ is completely absorbed from the stomach into blood and does not pass through the other compartments of the gastrointestinal tract (Zanzonico 2000). Three studies (excluding Franklyn et al. (1999)) concur in terms of increasing trend for stomach cancer (Hoffman et al. 1982, Holm et al. 1991, Metso et al. 2007) even though the meta-analysis of neither the digestive tract cancer on the whole nor the stomach cancer revealed increased risk. The strongest effect was with the study by Metso et al. (2007) (stomach cancer had 30 cases in the exposed group and an RR 1.76). In addition, stratification by duration of follow-up revealed significant increases in the SIR for stomach cancer (Holm et al. 1991). Data on the dependence of risk on radiation dose for stomach carcinogenesis in patients treated with radiation demonstrate that the slope (of the regression line fitted through the risk values as a function of dose) for the stomach is significantly positive (Suit et al. 2007) and it might therefore be prudent to consider caution especially in patients with a strong family history of gastric carcinoma (Meyer 1994).

Among other individual organs, we did find a higher risk of kidney cancer (RR 1.70). In terms of urinary cancers, others have found no increased risk to the bladder (Hoffman et al. 1982, Holm et al. 1991, Franklyn et al. 1999), though two studies (Holm et al. 1991, Metso et al. 2007) concur on renal cancer. Our pooled estimate for individual urinary organs suggests that the increased risk is mainly to the kidney. When we examined strata by duration of follow-up (Holm et al. 1991), the ratio of SIRs was not different from unity for kidney cancer. However, there were 90 cases of kidney cancer reported in three studies (Hoffman et al. 1982, Holm et al. 1991, Metso et al. 2007) and this raises concern. Fortunately, data from patients treated with radiation suggest that the RR (radiotherapy to general population) as a function of dose up to $15 \mathrm{~Gy}$ for the kidney is non-significantly positive and the curve for bladder is flat (Suit et al. 2007). Both the latter observation and the smaller dose expected to this organ are reassuring, but caution must still be exercised based on our results. Apart from kidney, thyroid and stomach, only risk of breast cancer has been suggested to be increased by one study (Metso et al. 2007) which is contrary to this meta-analysis and earlier studies (Hoffman \& McConahey 1983, Goldman et al. 1988, Holm et al. 1991).

\section{Conclusion}

The thyroid, kidney and stomach are the only three organs that remain under question in terms of increased cancer risk and need further investigation. While there is no demonstrable increased burden of risk overall 
after ${ }^{131} \mathrm{I}$ administration, the risks of thyroid, kidney and stomach cancers need to be kept in mind when individualising therapy. For example, it may be prudent to consider limiting use of ablative ${ }^{131} \mathrm{I}$ to patients without risk factors for the cancers in question. In the case of the thyroid, we could limit ablative use to diffuse toxic goitres or alternatively make efforts to follow-up stringently if administered for treatment of nodular disease. In addition, persons with a history of atrophic gastritis, intestinal metaplasia or dysplasia and gastric ulcers as well as a genetic predisposition to gastric cancer might also best be excluded. In the same way, subjects with acquired or genetic cystic diseases of the kidney, chronic hepatitis $\mathrm{C}$ infection, analgesic abuse, or who have received cytotoxic chemotherapy in childhood might also best avoid therapeutic ${ }^{131} \mathrm{I}$. Fortunately, diagnostic ${ }^{131}$ I has now been replaced by 99mTc-pertechnetate, so this is no longer of concern.

\section{Supplementary data}

This is linked to the online version of the paper at http://dx. doi.org/10.1530/ERC-12-0176.

\section{Declaration of interest}

The authors declare that there is no conflict of interest that could be perceived as prejudicing the impartiality of the research reported.

\section{Funding}

This research did not receive any specific grant from any funding agency in the public, commercial or not-for-profit sector.

\section{References}

AIHW 1998 Cancer in Australia 1998: incidence and mortality data for 1998. Australian Insitutes of Health and Welfare.

Angusti T, Codegone A, Pellerito R \& Favero A 2000 Thyroid cancer prevalence after radioiodine treatment of hyperthyroidism. Journal of Nuclear Medicine $\mathbf{4 1}$ 1006-1009.

Behar R, Arganini M \& Tain-Cheng W 1986 Graves' disease and thyroid cancer. Surgery 100 1121-1127.

Berlin NI \& Wasserman LR 1976 The association between systemically administered radioisotopes and subsequent malignant disease. Cancer 37 1097-1101. (doi:10.1002/ 1097-0142(197602)37:2 + <1097::AID-CNCR2820370 $818>3.0 . \mathrm{CO} ; 2-8)$

Bundi RS, Scott JS \& Halnan KE 1977 Chronic myeloid leukaemia following radioiodine therapy for carcinoma thyroid. British Journal of Radiology 50 61-64. (doi:10.1259/0007-1285-50-589-61)
Chapman EM \& Evans RD 1946 The treatment of hyperthyroidism with radioactive iodine. Journal of the American Medical Association 131 86-91. (doi:10.1001/ jama.1946.02870190010003)

Chaturvedi AK, Mbulaiteye SM \& Engels EA 2008 Underestimation of relative risks by standardized incidence ratios for aids-related cancers. Annals of Epidemiology $\mathbf{1 8}$ 230-234. (doi:10.1016/j.annepidem.2007.10.005)

Dickman PW, Holm LE, Lundell G, Boice JD \& Hall P 2003 Thyroid cancer risk after thyroid examination with I-131: a population-based cohort study in Sweden. International Journal of Cancer 106 580-587. (doi:10.1002/ijc.11258)

Dobyns BM, Sheline GE \& Workman JB 1974 Malignant and benign neoplasms of the thyroid in patients treated for hyperthyroidism: a report of the cooperative thyrotoxicosis therapy. Follow up study. Journal of Clinical Endocrinology and Metabolism 38 976-998.

(doi:10.1210/jcem-38-6-976)

Doi SA \& Thalib L 2008 A quality-effects model for meta-analysis. Epidemiology 19 94-100. (doi:10.1097/ EDE.0b013e31815c24e7)

Doi SA, Barendregt JJ \& Mozurkewich EL 2011 Meta-analysis of heterogeneous clinical trials: an empirical example. Contemporary Clinical Trials 32 288-298. (doi:10.1016/j.cct.2010.12.006)

Edmonds CJ \& Smith T 1986 The long-term hazards of the treatment of thyroid cancer with radioiodine. British Journal of Radiology 59 45-51. (doi:10.1259/0007-128559-697-45)

Franklyn JA, Maisonneuve P, Sheppard M, Betteridge J \& Boyle P 1999 Cancer incidence and mortality after radioiodine treatment for hyperthyroidism: a populationbased cohort study. Lancet 353 2111-2115. (doi:10.1016/ S0140-6736(98)12295-X)

Freitas JE, Swanson DP, Gross MD \& Sisson JC 1979 Iodine-131: optimal therapy for hyperthyroidism in children and adolescents? Journal of Nuclear Medicine 20 847-850.

Glinoer D, Hesch D, Lagasse R \& Laurberg P 1987 The management of hyperthyroidism due to Graves' disease in Europe in 1986. Results of an international survey. Acta Endocrinologica. Supplementum 285 3-23.

Goldman MB, Maloof F, Monson RR, Aschengrau A, Cooper DS \& Ridgway EC 1988 Radioactive iodine therapy and breast cancer. A follow-up study of hyperthyroid women. American Journal of Epidemiology 127 969-980.

Hahn K, Schnell-Inderst P, Grosche B \& Holm LE 2001 Thyroid cancer after diagnostic administration of iodine-131 in childhood. Radiation Research 156 61-70. (doi:10.1667/ 0033-7587(2001)156[0061:TCADAO]2.0.CO;2)

Hall P \& Holm LE 1995a Cancer in iodine-131 exposed patients. Journal of Endocrinological Investigation 18 147-149.

Hall P \& Holm LE 1995b Cancer incidence and mortality after I-131 therapy for hyperthyroidism. In Radiation and Public Perception: Benefits and Risks. Eds JP Young \& RS Yalow RS. Washington: Amer Chemical Soc. 
Hall P, Boice JD Jr, Berg G, Bjelkengren G, Ericsson UB, Hallquist A, Lidberg M, Lundell G, Mattsson A, Tennvall J et al. 1992 Leukaemia incidence after iodine-131 exposure. Lancet 340 1-4.

Hall P, Mattsson A \& Boice JD 1996 Thyroid cancer after diagnostic administration of iodine-131. Radiation Research 145 86-92. (doi:10.2307/3579200)

Hertz S \& Roberts A 1946 Radioactive iodine in the study of thyroid physiology; the use of radioactive iodine therapy in hyperthyroidism. Journal of the American Medical Association 131 81-86. (doi:10.1001/jama.1946. 02870190005002)

Hoffman DA \& McConahey WM 1983 Breast cancer following iodine-131 therapy for hyperthyroidism. Journal of the National Cancer Institute 70 63-67.

Hoffman DA, McConahey WM, Fraumeni JF Jr \& Kurland LT 1982 Cancer incidence following treatment of hyperthyroidism. International Journal of Epidemiology 11 218-224. (doi:10.1093/ije/11.3.218)

Hoffman DA, McConahey WM, Brinton LA \& Fraumeni JF Jr 1984 Breast cancer in hypothyroid women using thyroid supplements. Journal of the American Medical Association 251 616-619. (doi:10.1001/jama.1984. 03340290030015)

Holm LE, Dahlqvist I, Israelsson A \& Lundell G 1980 Malignant thyroid tumors after iodine-131 therapy: a retrospective cohort study. New England Journal of Medicine 303 188-191. (doi:10.1056/ NEJM198007243030404)

Holm LE, Wiklund KE, Lundell GE, Bergman NA, Bjelkengren G, Cederquist ES, Ericsson UB, Larsson LG, Lidberg ME, Lindberg RS et al. 1988 Thyroid cancer after diagnostic doses of iodine-131: a retrospective cohort study. Journal of the National Cancer Institute 80 1132-1138. (doi:10.1093/jnci/80. 14.1132)

Holm LE, Hall P, Wiklund K, Lundell G, Berg G, Bjelkengren G, Cederquist E, Ericsson UB, Hallquist A, Larsson LG et al. 1991 Cancer risk after iodine-131 therapy for hyperthyroidism. Journal of the National Cancer Institute 83 1072-1077. (doi:10.1093/jnci/83. 15.1072)

Huysmans D, Buijs W, van de Ven MT, van den Broek WJ, Kloppenborg PW, Hermus A \& Corstens FH 1996 Dosimetry and risk estimates of radioiodine therapy for large, multinodular goiters. Journal of Nuclear Medicine 37 2072-2079.

ICRP 1987 Radiation dose to patients from radiopharmaceuticals. Annals of the ICRP 18 1-171. (doi:10.1016/ 0146-6453(87)90003-0)

Jamal MH, Doi SA, Rousseau M, Edwards M, Rao C, Barendregt JJ, Snell L \& Meterissian S 2012 Systematic review and meta-analysis of the effect of North American working hours restrictions on mortality and morbidity in surgical patients. British Journal of Surgery 99 336-344. (doi:10.1002/bjs.8657)
Kennedy WM \& Fish RG 1959 Acute granulocytic leukemia after radioactive iodine therapy for hyperthyroidism. New England Journal of Medicine 260 76-77. (doi:10.1056/NEJM195901082600207)

Kloos RT 2011 Survey of radioiodine therapy safety practices highlights the need for user-friendly recommendations. Thyroid 21 97-99. (doi:10.1089/ thy.2010.2102.com)

Listewnik MH, Birkenfeld B, Chosia M, Elbl B, Niedziałkowska K \& Sawrymowicz M 2010 The occurrence of malignant thyroid lesions in patients after radioiodine treatment due to benign thyroid diseases. Endokrynologia Polska 61 454-457.

Lucignani G 2007 Long-term risks in hyperthyroid patients treated with radioiodine: is there anything new? European Journal of Nuclear Medicine and Molecular Imaging 34 1504-1509. (doi:10.1007/s00259-0070509-z)

McCormack KR \& Sheline GE 1963 Leukemia after radioiodine therapy for hyperthyroidism. California Medicine 98 207-209.

Mellemgaard A, From G, Jorgensen T, Johansen C, Olsen JH \& Perrild H 1998 Cancer risk in individuals with benign thyroid disorders. Thyroid $\mathbf{8}$ 751-754. (doi:10.1089/thy. 1998.8.751)

Metso S, Auvinen A, Huhtala H, Salmi J, Oksala H \& Jaatinen P 2007 Increased cancer incidence after radioiodine treatment for hyperthyroidism. Cancer 109 1972-1979. (doi:10.1002/cncr.22635)

Meyer MA 1994 Re: cancer risk after iodine-131 therapy for hyperthyroidism. Journal of the National Cancer Institute 86 1026-1027. (doi:10.1093/jnci/86.13.1026)

Morris JA \& Gardner MJ 1988 Calculating confidence intervals for relative risks (odds ratios) and standardised ratios and rates. BMJ 296 1313-1316. (doi:10.1136/bmj. 296.6632.1313)

Munoz JM, Gorman CA, Elveback LR \& Wentz JR 1978 Incidence of malignant neoplasms of all types in patients with Graves' disease. Archives of Internal Medicine 138 944-947. (doi:10.1001/archinte.1978. 03630310034015)

Ozaki O, Ito K, Mimura T, Sugino K, Kitamura Y, Iwabuchi H \& Kawano M 1994 Thyroid carcinoma after radioactive iodine therapy for Graves' disease. World Journal of Surgery 18 518-521. (doi:10.1007/BF00353753)

Pochin EE 1960 Leukaemia following radioiodine treatment of thyrotoxicosis. BMJ 2 1545-1550. (doi:10.1136/bmj.2. 5212.1545)

Read CH, Tansey MJ \& Menda Y 2004 A 36-year retrospective analysis of the efficacy and safety of radioactive iodine in treating young Graves' patients. Journal of Clinical Endocrinology and Metabolism 89 4229-4233. (doi:10.1210/jc.2003-031223)

Ron E 2003 Cancer risks from medical radiation. Health Physics 85 47-59. (doi:10.1097/00004032-20030700000011) 
Ross DS 2011 Radioiodine therapy for hyperthyroidism. New England Journal of Medicine 364 542-550. (doi:10.1056/NEJMct1007101)

Saenger EL, Thoma GE \& Tompkins EA 1968 Incidence of leukemia following treatment of hyperthyroidism. Journal of the American Medical Association 205 855-862. (doi:10.1001/jama.1968.03140380059014)

SNM 1999 Society of Nuclear Medicine Procedure Guideline for Thyroid Scintigraphy (online). Society of Nuclear Medicine. Available: http://interactive.snm.org/ docs/pg_ch05_0403.pdf (accessed 17/04/2012).

Solomon B, Glinoer D, Lagasse R \& Wartofsky L 1990 Current trends in the management of Graves' disease. Journal of Clinical Endocrinology and Metabolism 70 1518-1524. (doi:10.1210/jcem-70-6-1518)

Spencer RP, Chapman CN \& Rao H 1983 Thyroid carcinoma after radioiodide therapy for hyperthyroidism. Analysis based on age, latency, and administered dose of I-131. Clinical Nuclear Medicine 8 216-219. (doi:10.1097/ 00003072-198305000-00007)

Suit H, Goldberg S, Niemierko A, Ancukiewicz M, Hall E, Goitein M, Wong W \& Paganetti H 2007 Secondary carcinogenesis in patients treated with radiation: a review of data on radiation-induced cancers in human, nonhuman primate, canine and rodent subjects. Radiation Research 167 12-42. (doi:10.1667/RR0527.1)

Takkouche B, Cadarso-Suarez C \& Spiegelman D 1999 Evaluation of old and new tests of heterogeneity in epidemiologic meta-analysis. American Journal of Epidemiology 150 206-215. (doi:10.1093/oxfordjournals. aje.a009981)

Tominaga T, Yokoyama N, Nagataki S, Cho BY, Koh CS, Chen JL \& Shi Y 1997 International differences in approaches to 131I therapy for Graves' disease: case selection and restrictions recommended to patients in Japan, Korea, and China. Thyroid 7 217-220. (doi:10.1089/thy.1997.7.217)

Tucker MA, Jones PH, Boice JD Jr, Robison LL, Stone BJ, Stovall M, Jenkin RD, Lubin JH, Baum ES, Siegel SE et al. 1991 Therapeutic radiation at a young age is linked to secondary thyroid cancer. The late effects study group. Cancer Research 51 2885-2888.

Vaiserman AM 2010 Radiation hormesis: historical perspective and implications for low-dose cancer risk assessment. Dose-response: a Publication of International Hormesis Society 8 172-191.

de Vathaire F, Francois P, Schweisguth O, Oberlin O \& Le Monique G 1988 Irradiated neuroblastoma in childhood as potential risk factor for subsequent thyroid tumour. Lancet 2 455. (doi:10.1016/S0140-6736(88)90445-X)

Verburg FA, Luster M, Lassmann M \& Reiners C 2011 (131)I therapy in patients with benign thyroid disease does not conclusively lead to a higher risk of subsequent malignancies. Nuklearmedizin. Nuclear Medicine 50 93-99.

Walsh JP 2000 Management of Graves' disease in Australia. Australian and New Zealand Journal of Medicine 30 559-566. (doi:10.1111/j.1445-5994.2000.tb00856.x)

Zanzonico PB 2000 Age-dependent thyroid absorbed doses for radiobiologically significant radioisotopes of iodine. Health Physics 78 60-67. (doi:10.1097/00004032200001000-00010)

Received in final form 6 July 2012

Accepted 31 July 2012 Made available online as an Accepted Preprint 31 July 2012 